\title{
Ethiopian pre-school children consuming a predominantly unrefined plant-based diet have low prevalence of iron-deficiency anaemia
}

\author{
Dawd Gashu ${ }^{1, *}$, Barbara J Stoecker ${ }^{2}$, Abdulaziz Adish ${ }^{3}$, Gulelat D Haki ${ }^{4}$, Karim Bougma ${ }^{5}$ \\ and Grace $S$ Marquis ${ }^{5}$ \\ ${ }^{1}$ Center for Food Science and Nutrition, Addis Ababa University, PO Box 1176, Addis Ababa, Ethiopia: \\ ${ }^{2}$ Department of Nutritional Sciences, Oklahoma State University, Stillwater, OK, USA: ${ }^{3}$ Micronutrient Initiative \\ Africa, Addis Ababa, Ethiopia: ${ }^{4}$ Department of Food Science and Technology, University of Botswana, Botswana \\ College of Agriculture, Gaborone, Botswana: ${ }^{5}$ School of Dietetics and Human Nutrition, McGill University, \\ Ste-Anne-de-Bellevue, QC, Canada
}

Submitted 14 July 2015: Final revision received 18 November 2015: Accepted 9 December 2015: First published online 8 January 2016

\begin{abstract}
Objective: Children from low-income countries consuming predominantly plant-based diets but little animal products are considered to be at risk of Fe deficiency. The present study determined the $\mathrm{Fe}$ status of children from resource-limited rural households.

Design: A cross-sectional study.

Setting: Twenty six kebeles (the smallest administrative unit) from six zones of the Amhara region, Ethiopia.

Subjects: Children aged 54-60 months ( $n$ 628).

Results: Grain, roots or tubers were the main dietary components consumed by $100 \%$ of the study participants, followed by pulses, legumes or nuts (66.6\%). Consumption of fruit and vegetables (19.3\%) and meat, poultry and fish (2.2\%) was low. Children had a mean dietary diversity score of $2 \cdot 1$ (SD $0 \cdot 8$ ). Most children $(74.8 \%, n 470)$ were in the lowest dietary diversity group (1-2 food groups). Rate of any morbidity in the preceding $14 \mathrm{~d}$ was $22.9 \%$ ( $n$ 114). Infection or inflammation $\left(\alpha_{1}\right.$-acid glycoprotein $\left.>1.2 \mathrm{~g} / \mathrm{l}\right)$ was present in $30 \cdot 2 \%$ ( $n$ 184) of children. Children had a high rate of stunting (43.2\%). Of the total sample, $13.6 \%(n$ 82) of children were anaemic, $9 \cdot 1 \%(n$ 57) were Fe deficient and 5.3\% ( $n$ 32) had Fe-deficiency anaemia. Fe-deficiency erythropoiesis was present in $14.2 \%$ ( $n 60)$ of children. Conclusions: Despite consuming a predominantly plant-based diet and little animal-source foods, there was a low prevalence of Fe-deficiency anaemia. This illustrates that dietary patterns can be inharmonious with Fe biochemical status; thus, Fe-related interventions require biochemical screening.
\end{abstract}

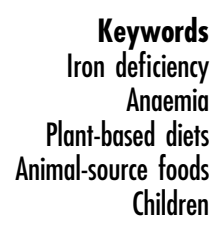

Fe deficiency is reported to be the world's most common single nutrient deficiency. One-quarter of the world's population is affected by anaemia and pre-school children are among the risk groups. The WHO estimates that $47 \%$ of children under 5 years of age are anaemic and that half of the anaemia prevalence can be attributed to Fe deficiency $^{(1)}$. The deficiency of Fe in children is associated with adverse mental, motor and socio-emotional development ${ }^{(2,3)}$. In addition, Fe deficiency during early life is a risk factor for poorer cognitive performance in adolescence even after children are $\mathrm{Fe}$ replete for several years $^{(4)}$.

Diets of rural populations in low-income countries are dominated by non-refined cereals and legumes which are rich in phytates that form insoluble complexes with $\mathrm{Fe}$, diminishing its bioavailability. Consumption of animalsource foods which contain readily bioavailable Fe and by themselves are Fe-absorption enhancers is low in these populations ${ }^{(5)}$. Thus, in addition to inadequate dietary intake, poor Fe bioavailability could be a major factor contributing to Fe-deficiency anaemia (IDA) ${ }^{(6)}$. Diets of rural Ethiopian populations are predominantly plant based with low intakes of animal-source foods ${ }^{(7)}$. Researchers have recognized the presence of mild to moderate IDA in lactating ${ }^{(8)}$ and pregnant ${ }^{(9)}$ women, as well as other women of reproductive age ${ }^{(10-12)}$, from Ethiopia. Recent studies have shown a high dietary intake of $\mathrm{Fe}$ by pregnant women $^{(13)}$ and young children ${ }^{(14)}$. 
Haider et $a l{ }^{(15)}$ reported that in Ethiopia the distribution of IDA varied by region and was dictated by the type of staple foods. Thus, as the country is agro-ecologically diverse and staple foods differ by area, the available data are not representative of the situation of the country. At present, except for small activities, Fe intervention programmes are not in place at the national scale. The national Fe advisory group suggested the need for more data for decision making. There is only one biochemical study available on Fe status of Ethiopian children $^{(6)}$. However, ferritin was not adjusted for inflammation or infection, which may underestimate the prevalence. That study reported presence of $18.6 \%$ of IDA but the estimation for IDA was based on a sub-sample of anaemic individuals.

It is generally assumed that anaemia and IDA are very common in populations from low-income countries with primarily plant-based diets but little animal-source foods. However, given the available reports showing only mild to moderate Fe deficiency in the country, this general assumption may not be appropriate for the Ethiopian context.

The present study investigated the Fe status of preschool children from resource-poor settings of the Amhara region who consumed a predominantly unrefined plantbased diet with little animal-source foods.

\section{Methods}

\section{Description of the research location}

The study was conducted in rural areas of the Amhara region, Ethiopia. The Amhara region is located in the north-western and north-central part of Ethiopia situated within $9^{\circ}$ and $13^{\prime} 45 \mathrm{~N}$ and $36^{\circ}$ and $40^{\prime} 30 \mathrm{E}$. It covers a total land area of $170000 \mathrm{~km}^{2}$. The region has a mean annual temperature in the range of 10 to $27^{\circ} \mathrm{C}$ and elevation between 500 and $4550 \mathrm{~m}$. According to the 2013 population projection for Ethiopia, the region has a total population of 20399004 and more than $90 \%$ live in rural areas. Agriculture is the main economic activity for the majority ( $85 \%$ ) of the population $^{(16,17)}$.

\section{Study design}

The present study was part of a large randomized controlled trial investigating the effect of iodized salt on cognitive development of iodine-deficient children. First, sixty districts from six zones (West Gojjam, East Gojjam, North Gondar, North Wollo, South Wollo and Wagehmera) of the Amhara region of Ethiopia were selected randomly. Subsequently, one rural kebele (the smallest administrative unit) from each of the selected sixty districts was randomly selected. In the selected kebeles, a house-to-house census was conducted to register all children aged 6-60 months. Then they were classified into three age groups (6-10 months, 18-22 months and 54-60 months) to control for age difference as a source of variation in cognitive performance, which was the primary objective of the randomized controlled trial. Child age was obtained from the immunization card or from the parents or guardian. An event calendar was prepared to help respondents remember birth dates. All children from the selected kebeles in the specified age range were included in the study. The single population proportion formula was used to determine sample size with $95 \%$ confidence level, $5 \%$ margin of error, design effect of 1.5 and $5 \%$ non-response rate. To maximize the sample size, $50 \%$ prevalence of Fe deficiency was considered. A sub-sample of all children aged 54-60 months ( $n$ 628) from twenty-six kebeles randomly selected from the original sixty kebeles were included. Data were collected between October 2011 and May 2012. Baseline data from the 54- to 60-month-old children are presented in the current paper.

\section{Data collection}

Research assistants were recruited and trained to standardized methods using structured protocols for data collection. A structured questionnaire that included questions about dietary intake, child morbidity, deworming medication, water and sanitation facilities available to households, and educational status of the mother and father or guardians of the selected children was used. The questionnaire was pre-tested in nonstudy households outside the study area before application.

\section{Dietary assessment}

A $24 \mathrm{~h}$ recall was used to assess dietary intake of the study children. Portion sizes were not collected. A list of thirty-one food items that could potentially be consumed by the study children was developed based on informal interviews and market and household observations. In addition, space was provided to record other food items consumed by the children but not listed. A food log book containing coloured pictures of different food items was prepared to be used as a reference to confirm responses of the mother or caregiver during a child feeding interview. Respondents were asked if the child consumed foods or foods prepared from any of the listed food items during the $24 \mathrm{~h}$ preceding the interview.

\section{Child morbidity}

Mothers or caregivers were asked whether their children experienced an episode of diarrhoea (passing watery stools three or more times per day), fever (fever with no other symptoms) or acute respiratory infection (episode of cough with short and rapid breathing) in the last $7 \mathrm{~d}$ and $14 \mathrm{~d}$ preceding the data collection. Malaria morbidity of children was also estimated by asking the mothers if they experienced common malaria symptoms (chills, fever, sweats and vomiting) and if the malaria infection was confirmed in the health post.

\section{Water and sanitation facilities}

Respondents were asked about the source of drinking-water and the type of toilet used by their household. Source of drinking-water and toilet facilities were categorized as 
improved or unimproved following the recommendation of the WHO/UNICEF Joint Monitoring Programme for Water Supply and Sanitation ${ }^{(18)}$.

\section{Educational status of guardians}

Respondents were asked if the mother, father or guardian of the selected children had formal education. In addition, for those with formal education, the respondents were asked the highest grade they attended.

\section{Anthropometric measurement}

Height was measured in erect position using a calibrated wooden height board (Stadiometer; Shorr Productions, Olney, MD, USA) with a sliding head bar while children were barefoot. Weight was measured using a battery-powered digital scale with a precision of $0.1 \mathrm{~kg}$ (TANITA WB-100; Tanita Corporation, Arlington Heights, IL, USA) while children wore light clothes, emptied pockets and no shoes. The weight scale was calibrated at least twice daily. The measurement was done twice and recorded to the nearest $0 \cdot 1 \mathrm{~kg}$. Height-for-age, weight-for-age and weight-for-height were converted into standardized $Z$-scores using WHO Anthro software and the data were used to classify the study children into categories of nutritional status, using the WHO reference curves $^{(19)}$. Children with height-for-age $Z$-score (HAZ) $<-2$, weight-for-age $Z$-score (WAZ $)<-2$ and weightfor-height $Z$-score (WHZ) $<-2$ were classified as stunted, underweight and wasted, respectively. Mid upper-arm circumference (MUAC) was also measured using a non-stretchable tape (MUAC Body Circumference Measuring Tape QM200; Quick Medical, Issaquah, WA, USA).

\section{Blood collection, handling and analyses}

Blood was collected by experienced nurses from the regional referral hospital (Felege Hiwote Hospital at Bahir Dar). Blood was drawn from the antecubital vein with disposable butterfly Vacutainer needles (BD Vacutainer butterfly needles, 23G, 3/4 in; Franklin Lakes, NJ, USA) using standard safety measures. The $\mathrm{Hb}$ level was measured immediately onsite using a digital photometer (HemoCue ${ }^{\circledR}$ $\mathrm{Hb} 201 \mathrm{DM}$; Ängelholm, Sweden). Altitude of the study kebeles was measured using an altimeter (Sunartis BKT 381, Germany). The blood samples were allowed to clot at ambient temperature and centrifuged in the field. The duplicate serum samples were transported to Bahir Dar in an ice box and kept at $-20^{\circ} \mathrm{C}$ until they could be transferred to Addis Ababa's Ethiopian Public Health Institute (EPHI) on dry ice, for storage at $-80^{\circ} \mathrm{C}$ until analysis. One vial of each frozen sample was shipped on dry ice to the Department of Nutritional Sciences at Oklahoma State University, USA, for Fe analysis.

Serum Fe was analysed by inductively coupled plasmamass spectrometry (ELAN9000; PerkinElmer, Norwalk, CT, USA). Serum samples were diluted in $0 \cdot 1 \%(\mathrm{v} / \mathrm{v})$ trace metal grade $\mathrm{HNO}_{3}$ (Fisher Scientific, Fair Lawn, NJ, USA). Working standards were freshly prepared by diluting $100 \mathrm{ppm}$ multi-element stock solution (Atomic Spectroscopy Standard PerkinElmer Pure Plus) in $0.1 \%(\mathrm{v} / \mathrm{v}) \mathrm{HNO}_{3}$ and $0.5 \%$ (v/v) Triton-X-100 (SIGMA Chemical Company, St. Louis, MO, USA) solution. Gallium (PerkinElmer) was used as an internal standard. A reference standard of freeze-dried human serum (Utak Laboratories, Inc., Valencia, CA, USA) was used to verify the method performance.

Serum ferritin was analysed using a fully automated clinical analyser (Electrochemilumenescense Immuno Assay (ECLIA) Elecsys $^{\circledR} 2010$ analyser, Cobas e 411; Roche Diagnostics $\mathrm{GmbH}$, Mannheim, Germany) at EPHI. Soluble transferrin receptor (sTFR) and $\alpha_{1}$-acid glycoprotein (AGP) were determined by immunoturbidimetric methods with a clinical chemistry analyser (Cobas Integra 400 system; Roche Diagnostics GmbH) at Saint Paulos Hospital, Addis Ababa. Fe deficiency was defined as serum ferritin $<12 \mu \mathrm{g} / \mathrm{l}$, and low $\mathrm{Hb}$ $(<110 \mathrm{~g} / \mathrm{l})$ with Fe deficiency was used to define IDA in children. Serum ferritin was adjusted for the presence of infection or inflammation using AGP. In the presence of infection or inflammation (AGP $>1.2 \mathrm{~g} / \mathrm{l}$ ), a serum ferritin value $<30 \mu \mathrm{g} / \mathrm{l}$ was used as a cut-off for Fe deficiency. An elevated serum sTFR indicates the presence of Fe-deficiency erythropoiesis (IDE) ${ }^{(20)}$. The normal reference range for sTFR for latex-enhanced immunoturbidimetric assay on the Cobas Integra 400 system is $2 \cdot 2$ to $5 \mathrm{mg} / \mathrm{l}$ as recommended by the manufacturer; $>5 \mathrm{mg} / \mathrm{l}$ was used as an indicator of IDE in the present study.

\section{Statistical analyses}

The statistical analysis of data was performed using the statistical software package PASW Statistics for Windows Version 18. Descriptive statistics were used to present results. Normal distribution of data was checked with the Kolmogorov-Smirnov test. Non-normally distributed data were analysed by non-parametric tests. The FAO guideline for measuring individual dietary diversity was used to assess diversity of children's food intake ${ }^{(21)}$. The dietary diversity score (DDS) was created by summing the different food groups (grain, roots or tubers; legumes, nuts or seeds; dark green leafy vegetables; other vitamin A-rich fruits and vegetables; other fruits and vegetables; organ meats; meat and fish; milk and milk products; eggs) consumed over the $24 \mathrm{~h}$ recall period. The DDS assigned 1 point for consumption of one or more food items in a group or 0 if no foods were consumed from the group. The children's DDS was further classified into three intake levels as low (1-2 food groups), medium (3-4 food groups) and high (5-8 food groups). Prevalence of stunting, underweight and wasting was compared between boys and girls using Student's $t$ test. Hb values were adjusted for altitude according to the formula by Sullivan et $a l^{(22)}$. Body Fe store was calculated according to the formula by Cook et $a l .{ }^{(23)}$. The level of sTFR in anaemic and non-anaemic children was compared using the Mann-Whitney test. Pearson correlation was used to identify bivariate correlations. A probability level of $P<0.05$ was considered statistically significant. 


\section{Results}

Characteristics of study participants are indicated in Table 1. The study children ( $n$ 628) had a male-to-female ratio of 1.01:1. The mean age of the children was 56.9 (SD 1.8) months with a range of 54-60 months. Of the total, $81 \cdot 7 \%$ ( $n$ 513) of fathers and $92.4 \%(n$ 580) of mothers had no formal education. A majority (54.2\%) of households had unimproved sources of drinking-water such that $16.6 \%$ of households used drinking-water from a lake, pond or river; and $37 \cdot 6 \%$ from unprotected springs. In addition, $28.3 \%$ ( $n$ 178) of the participants reported that they defecated outdoors in nature and $71.7 \%$ ( $n$ 450) had pit latrines. About 57.6\% ( $n$ 362) of the children had deworming medication six months preceding the interview.

Dietary intake of the children is indicated in Table 2. The dietary diversity score of the study children was in the range of $1-5$, with a mean value of $2 \cdot 1$ (SD $0 \cdot 8$ ). Most children, $74.8 \%$ ( $n$ 470), were in the lowest dietary diversity group consuming 1-2 food groups. Medium dietary diversity (3-4 food groups) and high dietary diversity (5-8 food groups) scores were attained by $24.0 \%$ ( $n$ 151) and $1 \cdot 1 \%(n 7)$ of the children, respectively. Grain, roots or tubers were consumed by $100 \%$ of the study children, followed by the food group comprising pulses, legumes or nuts as consumed by $66.6 \%$ of the participants. The dairy group was consumed by $21.7 \%$ ( $n$ 136), dark green leafy vegetables by $6.8 \%(n 43)$, other vitamin A-rich fruit and vegetables by $6.5 \%$ ( $n$ 41), other fruits and vegetables by $14.3 \%$ ( $n$ 90), meat, poultry and fish by $2 \cdot 2 \%$ ( $n$ 14) and eggs by $14 \cdot 3 \%$ ( $n$ 93) of the participants. None of the participants consumed organ meats in the $24 \mathrm{~h}$ preceding the interview.

For the two weeks preceding the survey, the overall rate of morbidity was $22.9 \%$ ( $n$ 144), with major

Table 1 Characteristics of households and child caregivers ( $n$ 628) from resource-poor rural households of the Amhara region, Ethiopia, October 2011-May 2012

\begin{tabular}{|c|c|c|}
\hline Characteristic & $n$ & $\%$ \\
\hline \multicolumn{3}{|l|}{ Education of the father } \\
\hline No education & 513 & $81 \cdot 7$ \\
\hline 1st-8th grade & 106 & $16 \cdot 9$ \\
\hline$\geq 9$ th grade & 9 & 1.4 \\
\hline \multicolumn{3}{|l|}{ Education of the mother } \\
\hline No education & 580 & $92 \cdot 4$ \\
\hline 1st-8th grade & 45 & $7 \cdot 1$ \\
\hline$\geq 9$ th grade & 3 & 0.5 \\
\hline \multicolumn{3}{|l|}{ Source of drinking-water } \\
\hline Dug well & 58 & $9 \cdot 2$ \\
\hline Lake, pond, river & 104 & $16 \cdot 6$ \\
\hline Pipe water & 125 & $19 \cdot 9$ \\
\hline Spring water* & 236 & $37 \cdot 6$ \\
\hline Tube well/bore hole & 105 & $16 \cdot 7$ \\
\hline \multicolumn{3}{|l|}{ Toilet facility } \\
\hline Pit latrines† & 450 & $71 \cdot 7$ \\
\hline Outdoors in nature & 178 & $28 \cdot 3$ \\
\hline
\end{tabular}

*Spring water was not of protected type.

†Pit latrines were not identified as whether covered or not. contributors being fever and cough (Table 3). A summary of the anthropometric characteristics of the study children is presented in Table 4. In the present study, $43.2 \%$ ( $n$ 271) of the children were stunted, 29.6\% ( $n$ 186) were underweight and $6.8 \%(n$ 43) were wasted. Prevalence of undernutrition was not statistically different $(P>0.05)$ between boys and girls (Table 5). Only one child had lower MUAC value.

The study children had altitude-corrected $\mathrm{Hb}$ levels in the range of $51.5-162.5 \mathrm{~g} / 1$ with a mean value of 120.4 (sD 10.7$) \mathrm{g} / \mathrm{l}$. Of the total, $13.6 \%$ ( $n$ 82) children were anaemic $(\mathrm{Hb}<110 \mathrm{~g} / \mathrm{l})$ and only two children were severely anaemic $(\mathrm{Hb}<70 \mathrm{~g} / \mathrm{l})$. Severely anaemic children were referred to the health post. A summary of Fe status parameters is indicated in Table 6. Inflammation or infection (AGP $>1.2 \mathrm{~g} / \mathrm{l}$ ) was present in $30 \cdot 2 \%$ ( $n$ 184) of the children. Fe deficiency was found in $9.1 \%$ ( $n$ 57) of the children. Serum ferritin concentration was positively correlated with AGP $(r=0 \cdot 16$, $P<0.01$ ). Only $5.3 \%$ ( $n$ 32) of the children had IDA and $2.9 \%$ ( $n$ 18) of the children were calculated to have a negative

Table 2 Percentage distribution of intake of different food items in the $24 \mathrm{~h}$ preceding the survey by children $(n 628)$ from resourcepoor rural households of the Amhara region, Ethiopia, October 2011-May 2012

\begin{tabular}{|c|c|c|}
\hline Food item & $n$ & $\%$ \\
\hline \multicolumn{3}{|l|}{ Cereals } \\
\hline Teff* $^{\star}$ & 476 & $75 \cdot 8$ \\
\hline Sorghum & 283 & $45 \cdot 1$ \\
\hline Millet & 173 & 27.5 \\
\hline Maize & 288 & $45 \cdot 9$ \\
\hline Wheat & 307 & 48.9 \\
\hline Barely & 224 & $35 \cdot 7$ \\
\hline Rice & 59 & 9.4 \\
\hline \multicolumn{3}{|l|}{ Pulses, legumes and nuts } \\
\hline Beans & 402 & $64 \cdot 0$ \\
\hline Lentils & 33 & $5 \cdot 3$ \\
\hline \multicolumn{3}{|l|}{ Roots and tubers } \\
\hline Sweet potato & 33 & $5 \cdot 3$ \\
\hline Potato & 160 & $25 \cdot 5$ \\
\hline \multicolumn{3}{|l|}{ Vegetables } \\
\hline Ğreen leafy vegetables & 43 & $6 \cdot 8$ \\
\hline Carrot & 5 & 0.8 \\
\hline Tomato & 7 & $1 \cdot 1$ \\
\hline Mango & 2 & 0.3 \\
\hline Papaya & 3 & 0.5 \\
\hline \multicolumn{3}{|l|}{ Animal-source foods } \\
\hline Eggs & 28 & 4.5 \\
\hline Chicken & 1 & 0.2 \\
\hline Beef & 9 & 1.4 \\
\hline Lamb & 3 & 0.5 \\
\hline Fish & 5 & 0.8 \\
\hline Milk & 137 & $21 \cdot 8$ \\
\hline \multicolumn{3}{|l|}{ Fruits } \\
\hline Lemon & 43 & $6 \cdot 8$ \\
\hline Orange & 39 & $6 \cdot 2$ \\
\hline Banana & 12 & 1.9 \\
\hline Guava & 13 & $2 \cdot 1$ \\
\hline Mango & 2 & 0.3 \\
\hline Papaya & 3 & 0.5 \\
\hline Avocado & 2 & 0.3 \\
\hline
\end{tabular}

${ }^{*}$ Teff is a gluten-free tiny cereal grain about the size of a poppy seed with variety of colours from white and red to dark brown. It is a staple crop to the majority of Ethiopians. 
body Fe store. Serum STFR was positively correlated with AGP $(r=0 \cdot 42, P<0 \cdot 01)$ but negatively correlated with serum Fe $(r=-0.14, \quad P<0 \cdot 01)$. Considering only those with AGP $\leq 1.2 \mathrm{~g} / 1,14.2 \%$ ( $n$ 60) of the children had elevated sTFR, suggesting the presence of IDE. The concentration of sTFR was higher in anaemic children than in those with normal $\mathrm{Hb}$ level $(P=0 \cdot 02)$. Using serum Fe $<600 \mu \mathrm{g} / \mathrm{l}$ as the cut-off for low Fe transport ${ }^{(24)}, 3 \cdot 2 \%$ ( $n$ 19) of the study children had low Fe transport.

\section{Discussion}

The present study investigated the Fe status of children from resource-limited rural households of the Amhara region, Ethiopia. Plant-based diets are expected to contain poorly bioavailable Fe. In addition, children from low-income countries have low consumption of animalsource foods, making them at risk of anaemia and IDA.

Table 3 Report of illness in the $7 \mathrm{~d}$ and $14 \mathrm{~d}$ preceding the interview among children ( $n 628)$ from resource-poor rural households of the Amhara region, Ethiopia, October 2011-May 2012

\begin{tabular}{lrrrrr}
\hline & \multicolumn{2}{c}{ Last 7d } & & \multicolumn{2}{c}{ Last 14d } \\
\cline { 2 - 3 } Illness & $n$ & $\%$ & & $n$ & $\%$ \\
\hline Diarrhoea & 22 & 3.5 & & 33 & 5.3 \\
Fever & 54 & 8.6 & & 64 & $10 \cdot 2$ \\
Malaria & 17 & 2.7 & & 23 & 3.7 \\
Cough & 69 & 11.0 & & 44 & 7.0 \\
Upper respiratory infection & 3 & 0.5 & & 4 & 0.6 \\
\hline
\end{tabular}

Table 4 Summary of anthropometric characteristics of children ( $n$ 628) from resource-poor rural households of the Amhara region, Ethiopia, October 2011-May 2012

\begin{tabular}{lrrrr}
\hline Variable & Minimum & Maximum & Mean & SD \\
\hline Weight $(\mathrm{kg})$ & 9.7 & 19.7 & 14.4 & 1.6 \\
Height $(\mathrm{cm})$ & 83.8 & 119.4 & 99.8 & 5.3 \\
MUAC $(\mathrm{mm})$ & 106.2 & 182.5 & 148.0 & 7.5 \\
WAZ & -4.3 & 0.6 & -1.5 & 0.8 \\
HAZ & -5.2 & 2.4 & -1.7 & 1.1 \\
WHZ & -3.0 & 2.2 & -0.7 & 0.8 \\
\hline
\end{tabular}

MUAC, mid upper-arm circumference; WAZ, weight-for-age Z-score; HAZ, height-for-age Z-score; WHZ, weight-for-height Z-score.
In view of the food patterns including low dietary diversity, high consumption of cereals and legumes, but very low consumption of fruit and vegetables, animalsource foods and vitamin A-rich foods, $\mathrm{Hb}$ concentration and $\mathrm{Fe}$ status of the present study children would have been predicted to be poor. However, despite the poor-quality diet, there was a very low prevalence of IDA. In addition, anaemia would be classified as only a mild public health problem.

The number of food groups consumed over a period of time is a proxy indicator for micronutrient intake. Low dietary diversity has been associated with dietary micronutrient deficiency in children ${ }^{(25,26)}$. Children from low-income countries typically experience monotonous or less diversified types of diets dominated by cereals, whole grains, roots and tubers ${ }^{(27)}$. Such unrefined plant-based staple foods often are rich in phytate that can bind and significantly reduce absorption of non-haem Fe due to the formation of insoluble Fe complexes ${ }^{(28,29)}$. Meat, fish and poultry are good sources of haem Fe of high bioavailability. In addition, the protein in animal-source foods can enhance absorption of Fe from non-haem sources attributed to the formation of soluble $\mathrm{Fe}$ complexes that prevent the precipitation of $\mathrm{Fe}$ in the lumen ${ }^{(30)}$. Vitamin $\mathrm{C}$ from fruits and vegetables is a powerful promoter of non-haem Fe absorption by reducing ferric $\left(\mathrm{Fe}^{3+}\right)$ into the more bioavailable ferrous form $\left(\mathrm{Fe}^{2+}\right)$. Ascorbic acid has also the ability to chelate $\mathrm{Fe}$ and consequently enhance absorption $^{(29)}$. Although the mechanism is not clear, carotenoids are also important in increasing the absorption of non-haem Fe from plant-based diets ${ }^{(31)}$. However, in the present study children, low consumption of animal-source foods and fruits and vegetables was observed. Milk and milk products contain low amounts of Fe. In addition, Ca and casein in cow's milk interfere with Fe absorption ${ }^{(32)}$. However, only about one-fifth of the study children consumed milk. A single $24 \mathrm{~h}$ dietary assessment is, however, limited for capturing day-to-day variability in food consumption. In addition, it suffers from recall bias ${ }^{(33)}$.

Because other food components and antinutitional factors interfere with Fe bioavailability, assessing only nutrient intake may not be a good indicator of Fe status. Studies in Ethiopia that assessed dietary intake of pregnant women ${ }^{(13)}$ and

Table 5 Nutritional status of children $(n$ 628) from resource-poor rural households of the Amhara region, Ethiopia, October $2011-$ May 2012

\begin{tabular}{|c|c|c|c|c|c|c|c|c|c|c|}
\hline \multirow[b]{3}{*}{ Variable } & \multicolumn{10}{|c|}{ Prevalence } \\
\hline & \multicolumn{2}{|c|}{ Overall* $^{*}$} & \multicolumn{2}{|c|}{ Moderate† } & \multicolumn{2}{|c|}{ Severe } & \multicolumn{2}{|c|}{ Boys (n 274) } & \multicolumn{2}{|c|}{ Girls (n 267) } \\
\hline & $n$ & $\%$ & $n$ & $\%$ & $n$ & $\%$ & $n$ & $\%$ & $n$ & $\%$ \\
\hline Stunting & 271 & $43 \cdot 2$ & 177 & $28 \cdot 2$ & 94 & $15 \cdot 0$ & 131 & $41 \cdot 3$ & 140 & $45 \cdot 0$ \\
\hline Underweight & 186 & $29 \cdot 6$ & 147 & 23.4 & 39 & $6 \cdot 2$ & 90 & 28.4 & 96 & 30.9 \\
\hline Wasting & 43 & $6 \cdot 8$ & 43 & $6 \cdot 8$ & 0 & 0.0 & 20 & $6 \cdot 3$ & 23 & $7 \cdot 4$ \\
\hline
\end{tabular}

*Overall $=$ Z-score $<-2$.

†Moderate $=Z$-score between -2 and -3 .

$\ddagger$ Severe $=Z$-score $<-3$. 
Table 6 Summary of biochemical parameters for iron status of children from resource-poor rural households of the Amhara region, Ethiopia, October 2011-May 2012

\begin{tabular}{|c|c|c|c|c|c|c|c|}
\hline \multirow[b]{2}{*}{ Variable } & \multirow[b]{2}{*}{$n$} & \multirow[b]{2}{*}{ Minimum } & \multirow[b]{2}{*}{ Maximum } & \multirow[b]{2}{*}{ Median } & \multirow[b]{2}{*}{ Q1, Q3 } & \multicolumn{2}{|c|}{ Proportion of deficient childrer } \\
\hline & & & & & & $n$ & $\%$ \\
\hline Ferritin $(\mu \mathrm{g} / \mathrm{l})$ & 621 & 1.5 & 393.8 & 44.5 & $29 \cdot 0,61 \cdot 8$ & 57 & $9 \cdot 1$ \\
\hline sTFR (mg/l) & 608 & $1 \cdot 1$ & $20 \cdot 0$ & 3.9 & $3 \cdot 4,5 \cdot 0$ & $60 \dagger$ & $14 \cdot 2$ \\
\hline Serum Fe $(\mu \mathrm{g} / \mathrm{l})$ & 602 & 397.9 & $5107 \cdot 1$ & $1330 \cdot 0$ & $1067 \cdot 1,1704 \cdot 4$ & 19 & $3 \cdot 2$ \\
\hline Body Fe $(\mathrm{mg} / \mathrm{kg})^{\star}$ & 608 & $-10 \cdot 7$ & $15 \cdot 1$ & $7 \cdot 1$ & $5 \cdot 3,8 \cdot 5$ & 18 & $2 \cdot 9$ \\
\hline
\end{tabular}

Q1, first quartile; Q3, third quartile; sTFR, soluble transferrin receptor.

*Body Fe was calculated based on the formula by Cook et al. ${ }^{(23)}$.

†Proportion was calculated for children ( $n$ 420) with $a_{1}$-glycoprotein $\leq 1.2 \mathrm{~g} / \mathrm{l}$.

young children ${ }^{(14)}$ consuming plant-based diets have shown that Fe was not a limiting nutrient per se. The present biochemical study found a low prevalence of Fe deficiency and IDA in children from the Amhara region. Cereals grown in Ethiopia have been reported to have high Fe content ${ }^{(7)}$. Part of this Fe, particularly for teff, was attributed to an extrinsic source from soil contamination during traditional threshing ${ }^{(34)}$. Indeed, some portion of this extrinsic Fe may be bioavailable ${ }^{(35)}$ and bioaccessible ${ }^{(36)}$. In addition, foods are frequently fermented and it has been shown that fermentation is effective to significantly reduce the phytate content of teff and other cereals to a level that can favour bioavailability $^{(7,34)}$. Further studies on identifying the factors contributing to the low prevalence of IDA in children from the Amhara region are important.

Anaemia is a major public health concern affecting one-quarter of the world's population. Pre-school children, particularly those from low-income countries, are at risk. The WHO World Anaemia Report estimated the prevalence of severe anaemia (75.2\%) in Ethiopian children ${ }^{(1)}$. However, the estimation was based on a predictive regression model using the 2002 UN Human Development Index and other social and economic variables such as life expectancy, education and wealth index, which are less appropriate than $\mathrm{Hb}$ measurement and may not be an accurate estimation of actual $\mathrm{Hb}$ level on the ground.

The present study children had also a lower anaemia prevalence compared with the 2011 Ethiopian Demographic and Health Survey ${ }^{(37)}$ for the Amhara region (35\%). Several reasons may explain this finding, including the difference in the data collection period of the two studies. Several nutrition and health interventions have been actively promoted including delivery of insecticide-treated mosquito nets, deworming medication and vitamin A supplementation. Additionally, anaemia prevalence normally shows a marked decline as children grow but the $35 \%$ prevalence in the Ethiopian Demographic and Health Survey report was for children under 5 years old in general, not specifically for those aged 54-60 months. In addition, even though the study districts and kebeles were selected randomly and all 54- to 60-month-old children from the selected kebeles were included, there may be variations within the Amhara region that were not captured in our data.
Dietary Fe is absorbed predominantly in the duodenum and temporarily held in the storage form of ferritin. Whenever the diet is unable to supply an adequate amount of Fe, the body's demand for Fe is maintained by the gradual release of the mineral from storage. Low ferritin concentration stimulates duodenal absorption of Fe. However, when absorption is not sufficient, body Fe storage depletes accompanied by a shortage in supply of $\mathrm{Fe}$ for $\mathrm{Hb}$ synthesis ${ }^{(38)}$. Serum ferritin is proportional to body Fe storage and is a reliable marker for the presence of Fe deficiency (serum ferritin $<12 \mu \mathrm{g} / 1$ in children). However, independent of Fe status, ferritin concentration can increase in the presence of inflammation or infection which affects its diagnostic efficiency ${ }^{(39)}$. In the present study children, serum ferritin concentration was positively correlated with AGP $(r=0 \cdot 16, P<0 \cdot 01)$, suggesting the influence of inflammation or infection on increasing serum ferritin level.

The concentration of sTFR is not as strongly affected as ferritin by the rise in acute-phase proteins due to infection or inflammation. This characteristic helps to discriminate IDA and anaemia of chronic disease. However, independent of Fe status, sTFR concentrations can increase due to clinical conditions such as megaloblastic anaemia and malaria infection that are common in children from poorresource settings ${ }^{(40,41)}$. The associated inflammation can increase hepcidin concentration which in turn prevents the release of Fe from duodenal absorptive cells or from Fe storage in the body ${ }^{(40)}$. For example, sTFR in the present study children was positively correlated with AGP, suggesting that inflammation or infection may partially explain the elevation of sTFR. An elevation of sTFR demonstrates the presence of IDE, which is characterized by a compromised plasma Fe supply to the bone marrow for erythrocyte synthesis. This condition can occur despite possessing normal or even excess storage of $\mathrm{Fe}$ and the term 'functional Fe deficiency' is commonly applied to describe the situation ${ }^{(39)}$. In the present study, anaemic children had higher levels of sTFR than normal children, which suggests that IDE could be one potential cause for low $\mathrm{Hb}$ concentration and a risk factor for anaemia. The influence of IDE on anaemia in the present study children warrants further study. 
High incidence of infection or inflammation (AGP $>1.2 \mathrm{~g} / \mathrm{l}$ ) was evident in the present study children. As a reaction to infection or inflammation, the concentration of acute-phase proteins is elevated ${ }^{(42)}$. Similarly, serum ferritin concentration increases in response to inflammation and can cause an underestimate of the overall Fe deficiency prevalence by up to $14 \%$. C-reactive protein (CRP) elevates and reaches its peak within 24 to $48 \mathrm{~h}$ of infection while AGP requires $4-5 \mathrm{~d}$ to become elevated. On the other hand, CRP declines rapidly a short time after the infection clears whereas AGP remains elevated. The combined use of CRP and AGP to catch such gaps and narrow underestimation of Fe deficiency has been recommended. It was estimated that the use of CRP or AGP alone can leave $9 \%$ and $5 \%$, respectively, of Fe deficiency undetected. However, the combined use of both CRP and AGP can reduce underestimation of Fe deficiency prevalence essentially to zero ${ }^{(43)}$. Soil helminthes, gastrointestinal parasitic infestation, malaria $^{(44,45)}$ or indoor air pollution ${ }^{(46,47)}$ could be some of the factors contributing to infection or inflammation in children from rural Ethiopia. In addition, $22.9 \%$ of children in the present study reported illness during the two weeks preceding the survey. However, the assessment of morbidity was not confirmed by medical tests and thus should be interpreted with caution. Only limited numbers of households in the present study had improved sources of drinking-water. In addition, even though the study was not able to identify covered $v$. open latrines, a vast majority of the households had pit latrines and at least $28.3 \%$ of the households defecated outdoors in nature; thus, limited access to quality water and sanitary facilities could be additional plausible explanations for the high incidence of infection or inflammation.

In general, the children in the present study had plantbased dietary patterns with very low intakes of animal-source foods; yet they had low prevalence of IDA. Thus, the assumption that monotonous plant-based diets with low intakes of animal-source foods will invariably lead to a high prevalence of IDA in populations from low-income countries may not be always correct. Furthermore, the high prevalence of infection and inflammation among children living in settings similar to our research site may be further exacerbated by Fe provision. Our findings have important programmatic implications in that programmes intended to correct Fe status must go beyond assumptions and predictive models. Screening for Fe status biomarkers needs to be considered, especially given the potential adverse consequences of $\mathrm{Fe}$ provision to Fe-replete children ${ }^{(48-50)}$.

\section{Acknowledgements}

Acknowledgements: The authors would like to thank the data collectors, health extension workers and study participants; Sandra Peterson for assistance with the serum Fe analyses; and EPHI and Saint Paulos Hospital for the analysis of Fe biomarkers. Financial support: This work was supported by the Micronutrient Initiative, Borlaug LEAP, the German Academic Exchange Service, and Addis Ababa University. The funders had no role in the design, analysis or writing of this article. Conflict of interest: None. Authorship: K.B. and G.S.M. developed the study design. D.G. and K.B. coordinated and supervised the field work. D.G. conducted the biochemical analysis. D.G. and B.J.S. analysed and interpreted the data. All authors contributed to manuscript preparation. Ethics of buman subject participation: This study was conducted according to the guidelines laid down in the Declaration of Helsinki and all procedures involving human subjects were approved by the National Health Research Ethics Review Committee at the Ethiopian Science and Technology Commission, and the Institutional Review Boards at McGill University, Canada and Oklahoma State University, USA. Written informed consent was obtained from all parents or guardians of the study children.

\section{References}

1. World Health Organization (2008) Worldwide Prevalence of Anaemia 1993-2005. WHO Global Database on Anaemia. Geneva: WHO.

2. Konofal E, Lecendreux M \& Arnulf I (2004) Iron deficiency in children with attention-deficit/hyperactivity disorder. Arch Pediatr Adolesc Med 158, 1113-1115.

3. Black MM, Quigg AM, Hurley KM et al. (2011) Iron deficiency and iron-deficiency anemia in the first two years of life: strategies to prevent loss of developmental potential. Nutr Rev 69, Suppl. 1, S64-S70.

4. Lozoff B, Jimenez E \& Smith JB (2006) Double burden of iron deficiency in infancy and low socioeconomic status: a longitudinal analysis of cognitive test scores to age 19 years. Arch Pediatr Adolesc Med 160, 1108-1113.

5. Neumann C, Harris DM \& Rogers LM (2002) Contribution of animal source foods in improving diet quality and function in children in the developing world. Nutr Res 22, 193-220.

6. Adish AA, Esrey SA, Gyorkos TW et al. (1999) Risk factors for iron deficiency anaemia in preschool children in northern Ethiopia. Public Health Nutr 2, 243-252.

7. Umeta M, West CE \& Fufa H (2005) Content of zinc, iron, calcium and their absorption inhibitors in foods commonly consumed in Ethiopia. J Food Compost Anal 18, 803-817.

8. Haidar J, Muroki NM, Omwega AM et al. (2003) Malnutrition and iron deficiency in lactating women in urban slum communities from Addis Ababa, Ethiopia. East Afr Med J 80, 191-194.

9. Gibson RS, Abebe Y, Stabler S et al. (2008) Zinc, gravida, infection, and iron, but not vitamin B-12 or folate status, predict hemoglobin during pregnancy in southern Ethiopia. J Nutr 138, 581-586.

10. Umeta M, Haidar J, Demissie T et al. (2008) Iron deficiency anaemia among women of reproductive age in nine administrative regions of Ethiopia. Ethiop J Health Dev 22, 252-258.

11. Haidar JA \& Pobocik RS (2009) Iron deficiency anemia is not a rare problem among women of reproductive ages in Ethiopia: a community based cross sectional study. $B M C$ Blood Disord 9, 7.

12. Haidar J (2010) Prevalence of anaemia, deficiencies of iron and folic acid and their determinants in Ethiopian women. J Health Popul Nutr 28, 359-368.

13. Abebe Y, Bogale A, Hambidge KM et al. (2008) Inadequate intakes of dietary zinc among pregnant women from subsistence households in Sidama, Southern Ethiopia. Public Health Nutr 11, 379-386. 
14. Baye K, Guyot JP, Icard-Verniére C et al. (2013) Nutrient intakes from complementary foods consumed by young children (aged 12-23 months) from North Wollo, Northern Ethiopia: the need for agro-ecologically adapted interventions. Public Health Nutr 16, 1741-1750.

15. Haidar J, Nekatibeb H \& Urga K (1999) Iron deficiency anaemia status in pregnant and lactating mothers of various staple areas in rural Ethiopia. East Afr Med J 76, 618-622.

16. Central Statistical Agency of Ethiopia (2013) Population Projection of Ethiopia for all Regions at Woreda Level from 2014-2017. Addis Ababa: CSA.

17. Motbainor A, Worku A \& Kumie A (2015) Stunting is associated with food diversity while wasting with food insecurity among underfive children in East and West Goijam zones of Amhara region, Ethiopia. PLoS One 10, e0133542.

18. World Health Organization/UNICEF (2000) Joint Monitoring Programme for Water Supply and Sanitation. Global Water Supply and Sanitation Assessment 2000 Report. Washington, DC: WHO/UNICEF.

19. WHO Multicenter Growth Reference Study Group (2006) WHO Child Growth Standards: Length/Height-for-Age, Weight-for-Age, Weight-for-Length, Weight-for-Height and Body Mass Index-for-Age: Methods and Development. Geneva: WHO.

20. World Health Organization/UNICEF/International Council for the Control of Iron Deficiency Disorders (2001) Iron Deficiency Anemia: Assessment, Prevention and Control. Geneva: WHO.

21. Kennedy G, Ballard T \& Dop MC (2011) Guidelines for Measuring Household and Individual Dietary Diversity. Rome: FAO.

22. Sullivan KM, Mei Z, Grummer-Strawn L et al. (2008) Haemoglobin adjustments to define anaemia. Trop Med Int Health 13, 1267-1271.

23. Cook JD, Flowers CH \& Skikne BS (2003) The quantitative assessment of body iron. Blood 101, 3359-3364.

24. Cook JD, Baynes RD \& Skikne BS (1992) Iron deficiency and the measurement of iron status. Nutr Res Rev 5, 189-202.

25. Steyn NP, Nel JH \& Nantel G (2006) Food variety and dietary diversity scores in children: are they good indicators of dietary adequacy? Public Health Nutr 9, 644-650.

26. Kennedy GL, Pedro MR \& Seghieri C (2007) Dietary diversity score is a useful indicator of micronutrient intake in nonbreast-feeding Filipino children. J Nutr 137, 472-477.

27. Thompson B \& Amoroso L (editors) (2011) Combating Micronutrient Deficiencies: Food-Based Approaches. Rome: FAO and CABI.

28. Gibson RS, Perlas L \& Hotz C (2006) Improving the bioavailability of nutrients in plant foods at the household level. Proc Nutr Soc 65, 160-168.

29. Hurrell R \& Egli I (2010) Iron bioavailability and dietary reference values. Am J Clin Nutr 91, Suppl. 5, S1461-S1467.

30. Bæch SB, Hansen M, Bukhave K et al. (2003) Nonheme-iron absorption from a phytate-rich meal is increased by the addition of small amounts of pork meat. Am J Clin Nutr $\mathbf{7 7}$, 173-179.

31. García-Casal MN (2006) Carotenoids increase iron absorption from cereal-based food in the human. Nutr Res 26, 340-344.

32. Ziegler EE (2011) Consumption of cow's milk as a cause of iron deficiency in infants and toddlers. Nutr Rev 69 Suppl. 1, S37-S42.

33. Gibson RS (2005) Principles of Nutritional Assessment, 2nd ed. New York: Oxford University Press, Inc.
34. Abebe Y, Bogale A, Hambidge KM et al. (2007) Phytate, zinc, iron and calcium content of selected raw and prepared foods consumed in rural Sidama, Southern Ethiopia, and implications for bioavailability. J Food Compost Anal 20, $161-168$

35. Gibson RS, Wawer AA, Fairweather-Tait SJ et al. (2015) Dietary iron intakes based on food composition data may underestimate the contribution of potentially exchangeable contaminant iron from soil. J Food Compost Anal 40, 19-23.

36. Greffeuille V, Kayodé AP, Icard-Vernière C et al. (2011) Changes in iron, zinc and chelating agents during traditional African processing of maize: effect of iron contamination on bioaccessibility. Food Chem 126, 1800-1807.

37. Central Statistical Agency of Ethiopia \& ICF International (2012) Ethiopia Demographic and Health Survey 2011. Addis Ababa and Calverton, MD: CSA and ICF International.

38. Geissler C \& Singh M (2011) Iron, meat and health. Nutrients 3, 283-316.

39. Cook JD (2005) Diagnosis and management of irondeficiency anaemia. Best Pract Res Clin Haematol 18, 319-332.

40. Zimmermann MB (2008) Methods to assess iron and iodine status. Br J Nutr 99, Suppl. 3, S2-S9.

41. Menendez C, Quinto LL, Kahigwa E et al. (2001) Effect of malaria on soluble transferrin receptor levels in Tanzanian infants. Am J Trop Med Hyg 65, 138-142.

42. Wieringa FT, Dijkhuizen MA, West CE et al. (2002) Estimation of the effect of the acute phase response on indicators of micronutrient status in Indonesian infants. J Nutr 132, 3061-3066.

43. Thurnham DI, McCabe LD, Haldar S et al. (2010) Adjusting plasma ferritin concentrations to remove the effects of subclinical inflammation in the assessment of iron deficiency. Am J Clin Nutr 92, 546-555.

44. Alemu A, Atnafu A, Addis Z et al. (2011) Soil transmitted helminths and Schistosoma mansoni infections among school children in Zarima town, northwest Ethiopia. BMC Infect Dis 11, 189.

45. Alemu A, Shiferaw Y, Ambachew A et al. (2012) Malaria helminth co-infections and their contribution for aneamia in febrile patients attending Azzezo health center, Gondar, Northwest Ethiopia. Asian Pac J Trop Med 5, 803-809.

46. Bruce N, Perez-Padilla R \& Albalak R (2000) Indoor air pollution in developing countries: a major environmental and public health challenge. Bull World Health Organ 78, 1078-1092.

47. Fullerton DG, Bruce N \& Gordon SB (2008) Indoor air pollution from biomass fuel smoke is a major health concern in the developing world. Trans R Soc Trop Med Hyg 102, 843-851.

48. Lind T, Seswandhana R, Persson LÅ et al. (2008) Iron supplementation of iron-replete Indonesian infants is associated with reduced weight-for-age. Acta Paediatr 97, $770-775$.

49. Majumdar I, Paul P, Talib VH et al. (2003) The effect of iron therapy on the growth of iron-replete and iron-deplete children. J Trop Pediatr 49, 84-88.

50. Jaeggi T, Kortman GAM, Moretti D et al. (2015) Iron fortification adversely affects the gut microbiome, increases pathogen abundance and induces intestinal inflammation in Kenyan infants. Gut 64, 731-742. 